\title{
Microstructural Characterization of Metal Injection Molded (MIM) AISI 316L
}

\author{
S. R. Collins*
}

*Swagelok Company, 29500 Solon Road, Solon, OH 44139

Metal injection molding is a technologically intensive method by which net shape or near-net shape components are manufactured. The process involves injection molding of a feedstock containing very fine metal powder compounded with a polymer binder. After molding, most of the binder is removed by aqueous or vapor phase methods, and the component is sintered in a furnace. The powder particles fuse together to reach $96-99 \%$ of theoretical density. The component experiences some shrinkage, usually around $20 \%$ or less.

Six groups of MIM 316L specimens were obtained from four commercial producers of MIM components. The specimens were evaluated for composition and microstructure. Microstructural characteristics measured for each group included density, porosity, ferrite, grain size, microhardness, and surface roughness as received.

All six materials had the following microstructural features in common:

- The structure was fully annealed, as evidenced by low microhardness readings (69 to $81 \mathrm{HRB}$ ), blocky grains and relative absence of twins.

- The structure was isotropic (non-directional). This is unusual for AISI 316L; bar stock usually has different properties in the transverse and longitudinal directions as a result of thermomechanical working to achieve a usable product form.

- The pores were small and rounded, and were located preferentially within the grains and not on the grain boundaries.

- A fully dense skin of approximately $300 \mu \mathrm{m}$ was found at the surface of the parts.

- Inclusions found in the microstructures included manganese sulfides (also on the surface of the parts), silica-based and alumina-based inclusions.

- A second phase rich in $\mathrm{Fe}$ and $\mathrm{Cr}$ was found on the grain boundaries as ferrite increased and porosity decreased.

Correlations between composition and microstructure indicate the following fundamental relationships:

- Density, ferrite content, and porosity are strongly correlated. As ferrite increases, density increases and porosity decreases.

- Grain size and microhardness are related; smaller grains result in increased microhardness. 
Table 1. MIM 316L: Range of Compositions Evaluated

\begin{tabular}{|l|c|c|}
\hline $\begin{array}{l}\text { Element, } \\
\text { wt\%** }\end{array}$ & MIM 316L* & AISI 316L \\
\hline $\mathbf{C}$ & $0.002-0.031$ & $0.030 \mathrm{max}$ \\
\hline $\mathbf{M n}$ & $0.06-1.34$ & $2.00 \mathrm{max}$ \\
\hline $\mathbf{P}$ & $0.013-0.023$ & $0.045 \mathrm{max}$ \\
\hline $\mathbf{S}$ & $0.002-0.007$ & $0.030 \mathrm{max}$ \\
\hline $\mathbf{S i}$ & $0.05-0.061$ & $0.75 \mathrm{max}$ \\
\hline $\mathbf{C r}$ & $16.46-17.49$ & $16.00-18.00$ \\
\hline $\mathbf{N i}$ & $10.51-12.55$ & $10.00-14.00$ \\
\hline $\mathbf{M o}$ & $2.1-2.66$ & $2.00-3.00$ \\
\hline $\mathbf{N}$ & $0.002-0.04$ & $0.10 \mathrm{max}$ \\
\hline
\end{tabular}

*Six lots of material from four suppliers

**Other elements evaluated: $\mathrm{Al}, \mathrm{Cu}, \mathrm{O}, \mathrm{Ti}, \mathrm{Co}$,

$\mathrm{Nb}, \mathrm{Ca}, \mathrm{Se}$

Table 2. MIM 316L: Evaluated Properties

\begin{tabular}{|l|c|}
\hline Property & Range of values \\
\hline Density, g/cm & $7.48-7.89$ \\
\hline Porosity, \% & $0.06-8.85$ \\
\hline Ferrite, \% & $0-5.16$ \\
\hline Grain size & $5.5-7$ \\
\hline Microhardness, HV & $122.8-153.4$ \\
\hline Hardness, HRB & $69-81$ \\
\hline $\begin{array}{l}\text { Surface roughness, Ra } \\
\text { avg. }\end{array}$ & $23-52$ \\
\hline
\end{tabular}

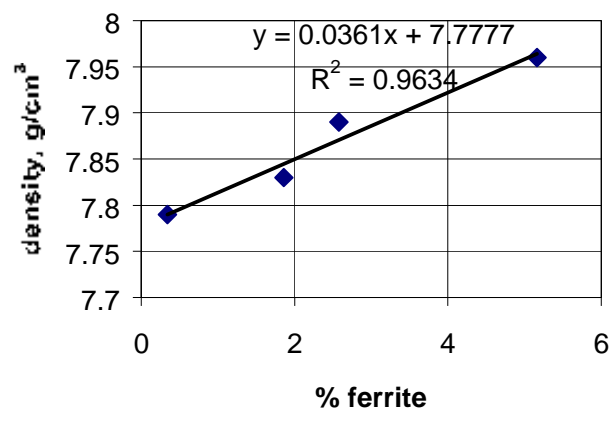

Fig. 1 MIM 316L: Density vs \% Ferrite

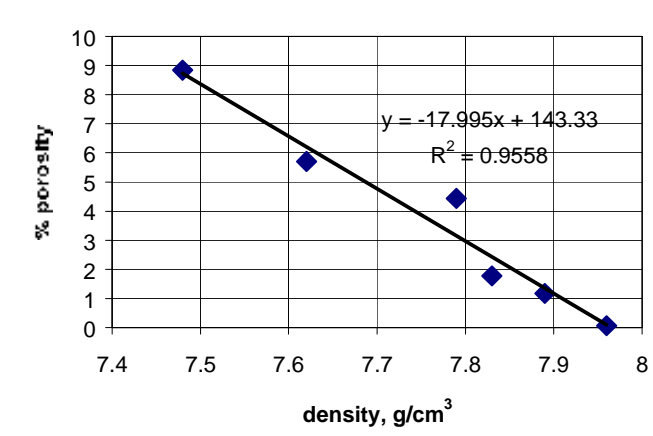

Fig. 2 MIM 316L: \% Porosity vs Density

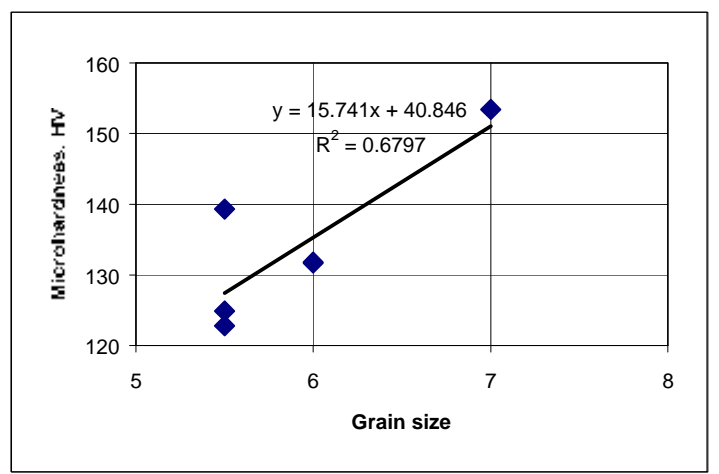

Fig. 3 MIM 316L: Microhardness vs Grain Size

Fig. 4 (a and b) MIM 316L: Representative Microstructures

SEM, polished and etched. (a) Material with $0 \%$ ferrite and $5.7 \%$ porosity. (b) Material with $5.17 \%$ ferrite and $0.06 \%$ porosity.
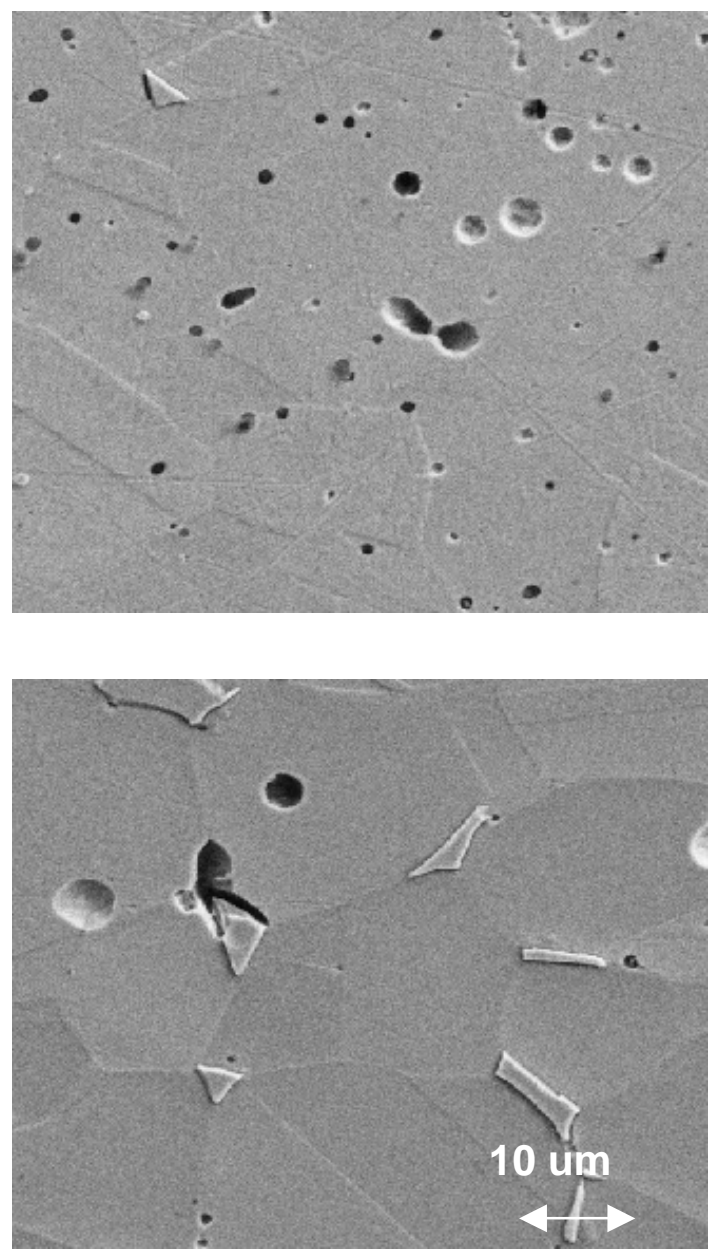